\title{
High-dose, unlabeled, nonspecific antibody pretreatment: influence on specific antibody localization to human melanoma xenografts
}

\author{
Richard L. Wahl ${ }^{1}$, Barry S. Wilson ${ }^{2}$, Monica Liebert ${ }^{1}$, and William H. Beierwaltes ${ }^{1}$ \\ ${ }^{\prime}$ University of Michigan Medical Center, Department of Internal Medicine, Division of Nuclear Medicine \\ ${ }^{2}$ Department of Pathology Ann Arbor, Michigan, USA
}

\begin{abstract}
Summary. Nonspecific uptake of radiolabeled monoclonal antibodies in normal tissues is a significant problem for tumor imaging. A potential means of decreasing nonspecific antibody binding is to "blockade" nonspecific antibody binding sites by predosing with cold, nonspecific isotypematched antibody, before injecting specific antibody. Nontumor-specific murine monoclonal antibody LK2H10 (IgG1) or Ab-1 (IgG2a) was given i.v. at doses of 0 to $3.5 \mathrm{mg}$ to nude mice with xenografts of human melanoma. These mice were then given i.v. $4 \mu \mathrm{g}$ of ${ }^{131} \mathrm{I}$ anti-high molecular weight antigen of melanoma (HMWMAA) monoclonal antibody $763.24 \mathrm{~T}$ (IgG1) or $225.28 \mathrm{~S}$ (IgG2a), respectively. These mice were also given a tracer dose of ${ }^{125} \mathrm{I}$ LK2H10 or Ab-1, respectively. Specific tumor uptake of anti-HMWMAA antibodies was see in all cases. No drop in tumor or nontumor uptake was demonstrated for either of the tumor-specific or nonspecific monoclonal antibodies due to nonspecific monoclonal antibody pretreatment. These data suggest that high doses of isotype-matched unlabeled nonspecific monoclonal antibody given before ${ }^{131} \mathrm{I}$ tumor-specific monoclonal antibody, will not enhance tumor imaging.
\end{abstract}

\section{Introduction}

Nonspecific accumulation of radiolabeled monoclonal antibodies reactive with tumor-associated antigens, in a variety of normal tissues is a limitation to their widespread clinical utility [16]. While antibody fragments have been shown to improve this problem, their production can be difficult in some cases, and absolute tumor uptakes are generally lower than those of intact antibody [3, 12, 17].

Some uptake of intact antibodies to nontarget organs may be due to interactions of the F-C portion of IgG antibodies with cells of the reticuloendothelial system (RES) [17]. While antibody fragments eliminate the possibility of such F-C interactions, an alternative approach would be to saturate or blockade these RES sites (F-C gamma receptors present in the liver, spleen, lungs, and bone marrow) by high doses of unlabeled nonspecific antibody. Three

\footnotetext{
* Present address: Hybritech, San Diego, CA, USA Offprint requests to: Richard L. Wahl, University of Michigan Medical Center, Division of Nuclear Medicine, 1500 East Medical Center Drive, Ann Arbor, MI 48109-0028, USA
}

types of F-C gamma receptors have been described, two of which have low affinity for monomeric IgG and one of which has high affinity [2]. Since different isotypes of monoclonal antibodies may potentially have differential binding to F-C gamma receptors, such RES blockade would seem most effectively mediated by an isotypematched nonspecific antibody.

There is also a precedent for RES blockade in man, in the case of successful treatment with unlabeled nonspecific IgG improve platelet survival duration in indiopathic thrombocytopenic purpura [8]. The aim of our investigation was to determine if "RES blockade" with a high dose of unlabeled isotype-matched monoclonal antibody was effective in enhancing specific monoclonal antibody localization (or in decreasing nonspecific organ accumulation by F-C gamma blockade) to human melanoma xenografts in a nude mouse model of human melanoma.

\section{Materials and methods}

Monoclonal antibodies. 225.28S (murine IgG2ak) and 763.24T (murine IgG1K) are reactive with a high molecular weight antigen present on the surface of most melanomas [5, 22]. The $225.28 \mathrm{~S}$ has previously been shown to localize largely due to antibody specificity to human melanoma xenografts and has successfully imaged melanoma in humans $[1,6,15]$. The AB-1 (murine IgG2ak) is reactive with the receptor for the $\mathrm{C} 3 \mathrm{~d}$ human complement component but is not known to react with murine complement determinants [23]. The LK2H10 (murine IgG1k) is a monoclonal antibody reactive with chromogranin of human origin, but not with mouse determinants [21]. All hybridomas were grown as ascities in BALB/c mice. The IgG2a antibodies were purified by staphylococcal protein A chromatography, while the IgGls were purified by DEAE chromatography $[4,17]$. The purity of preparations was confirmed by $7.5 \%$ sodium dodecyl sulfate polyacrylamide gel electrophoresis [9].

Antibody labeling. The iodobead method was used to label each monoclonal antibody [13]. In general 2 iodobeads and $1 \mathrm{mCi}$ of ${ }^{131} \mathrm{I}$ or ${ }^{125} \mathrm{I}$ were used to label $50-100 \mu \mathrm{g}$ of purified antibody. Free iodine was removed by separation over a Biogel P-60 sizing column (Biorad). Yields of $40 \%-70 \%$ were typical, with a final specific activity of approximately $4-7 \mu \mathrm{Ci} / \mu \mathrm{g}$. The lack of free iodine contamination in the preparations was confirmed by silica gel 
thin-layer chromatography using $50 \%$ ethanol and 50\% ethyl acetate as a solvent [20]. Labeled antibodies were tested for binding by a direct cell binding assay to HTB-63 melanoma cells in which $5 \times 10^{6}$ cells were reacted with increasing dilutions of antibody in efforts to achieve antigen excess. These binding assays were carried out at $37^{\circ} \mathrm{C}$ for $1 \mathrm{~h}[10,20]$.

Animal model. Female nu/nu mice 4 to 6 weeks old were injected s. c. with $10 \times 10^{6}$ HTB-63 human melanoma cells. Solid tumors were palpable 3-4 weeks later. When tumors were at least $5 \mathrm{~mm}$ in diameter, mice were studied.

Localization study. The $\operatorname{IgG} 2 \mathrm{aK}$ monoclonal antibody $\mathrm{AB}-1$ was given i.v. to groups of tumor-bearing animals at doses of $0 \mu \mathrm{g}$ (normal saline), $500 \mu \mathrm{g}$, and $2500 \mu \mathrm{g}$. Approximately $1 \mathrm{~h}$ later these doses were followed by an i.v. injection of a mixture of $30 \mu \mathrm{Ci}$ of ${ }^{131} \mathrm{I} 225.28 \mathrm{~S}$ and $15 \mu \mathrm{Ci}$ of ${ }^{125} \mathrm{I}$ AB-1 (4 and $2 \mu \mathrm{g}$, respectively). Animals were sacrificed 7 days after injection and tissues weighed and counted. After correction for spillover and physical decay, percent kilogram dose per gram and tumor/nontumor ratios were determined using standard tissue processing techniques [18, 19].

A similar experiment was conducted for the IgG1 antibody, LK2-H10. This unlabeled murine monoclonal an tibody, without specificity for mouse proteins, was given to groups of tumor-bearing animals at dose of $0 \mu \mathrm{g}$ (normal saline) $1000 \mu \mathrm{g}$, and $3500 \mu \mathrm{g}$. Then $1 \mathrm{~h}$ later, animals were given a dual-label injection of $30 \mu \mathrm{Ci}$ of ${ }^{131} \mathrm{I} 763.24 \mathrm{~T}$ (anti-melanoma) and $15 \mu \mathrm{Ci}$ of ${ }^{125} \mathrm{I}$ LK2H10 i.v. Animals were then maintained on Lugol's iodine, with sacrifice and tissue counting 8 days after injection.

Statistical analysis was by the Student's $t$-test with correction for small sample sizes and ANOVA.

\section{Results}

The HTB-63 antigen-positive melanoma target cells of 763.24T and $225.28 \mathrm{~S}$ showed strong specific binding with immunoreactive fractions of $48 \%$ and $58 \%$ respectively after a 1 -h incubation. AB- 1 and LK2H10 by contrast had only nonspecific binding to HTB-63 cells of $1.7 \%$ and $0.2 \%$ of input counts.

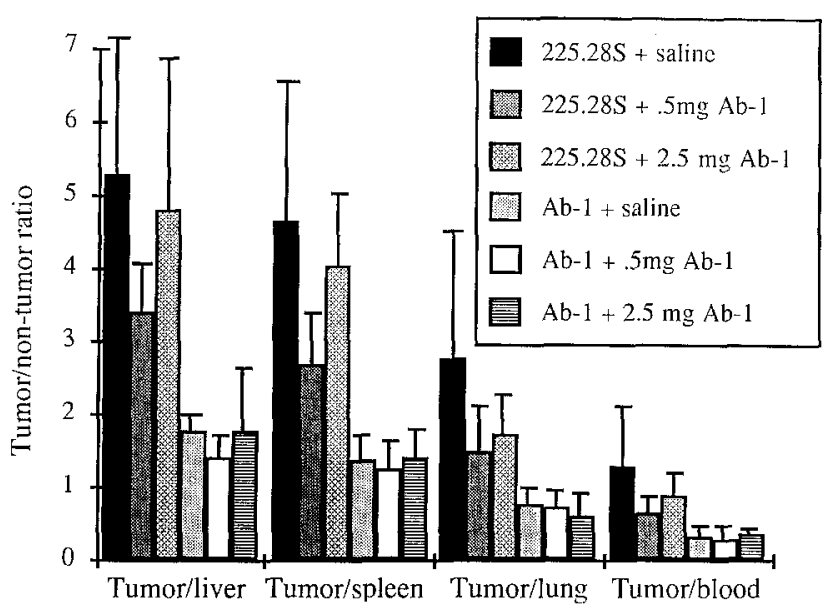

Fig. 1. Mean \pm SEM of tumor/nontumor uptake ratios $(\% \mathrm{~kg}$ dose $/ \mathrm{g}$ tumor $/ \% \mathrm{~kg}$ dose $/ \mathrm{g}$ nontumor) for $225.28 \mathrm{~S}$ and $\mathrm{Ab}-17$ days after injection. Note the lack of significant difference within the specific antibody and the nonspecific antibody groups. By contrast, the localization of $225.28 \mathrm{~S}$ was significantly better than that of Ab-1 $(P<0.01)$

Tissue distributions 7 days following the i.v. injection of ${ }^{131} \mathrm{I} 225.28 \mathrm{~S}$ and ${ }^{125} \mathrm{I} \mathrm{AB}-1$ are shown in Fig. 1 as indicated by tumor/nontumor ratios. There was no alteration in the biodistribution of the specific anti-melanoma antibody despite the high-dose nonspecific antibody pretreatment (Fig. 1). No change in the biodistribution of Ab-1 nonspecific antibody was seen either ( $P=$ NS by ANOVA). Tumor/nontumor ratios were significantly higher for the 225.28S than for the Ab-1 $(P<0.01)$.

Tissue distributions following the i.v. injection of ${ }^{131} \mathbf{I}$ 763.24T and ${ }^{125}$ I LK2H10 are shown as tumor/nontumor ratios in Fig. 2. There was no alteration ( $P=$ NS by ANO$\mathrm{VA}$ ) in the distribution of these $\operatorname{IgG} 1$ kappa antibodies following a variety of levels of pretreatment with nonspecific IgG1 (anti-CG). Again, tumor/nontumor ratios were significantly higher for the 763.24T-specific monoclonal antibody than for the LK2H10 $(P<0.01)$, indicating specific tumor uptake of these reagents. Table 1 shows blood uptake of the two antibodies as related to predose of cold antibody. Table 2 indicates uptake to tumor, while Table 3 shows mean tumor weights.

Table 1. $\% \mathrm{Kg}$ dose $/ \mathrm{g}$ in blood $\pm \mathrm{SD} 7$ to 8 days after injection

\begin{tabular}{|c|c|c|c|c|c|}
\hline & $A b-1$ & $225.28 \mathrm{~S}$ & LK2H10 & $763.24 \mathrm{~T}$ & \\
\hline Predose $=$ saline & $0.197 \pm 0.078$ & $0.047 \pm 0.028$ & $0.104 \pm 0.003$ & $0.081 \pm 0.0008$ & $(n=5)$ \\
\hline $\begin{array}{l}\text { Isotype-matched low-dose nonspecific } \\
\text { monoclonal antibody }\end{array}$ & $0.312 \pm 0.061$ & $0.110 \pm 0.050$ & $0.099 \pm 0.010$ & $0.081 \pm 0.008$ & $(n=7)$ \\
\hline $\begin{array}{l}\text { Isotype-matched high-dose nonspecific } \\
\text { monoclonal antibody }\end{array}$ & $0.210 \pm 0.04$ & $0.073 \pm 0.018$ & $0.106 \pm 0.034$ & $0.086 \pm 0.028$ & $(n=5)$ \\
\hline
\end{tabular}

Table $2 . \% \mathrm{Kg}$ dose $/ \mathrm{g}$ injected reaching tumor \pm SEM 7 to 8 days after injection

\begin{tabular}{lllll}
\hline & Ab-1 & $225.28 \mathrm{~S}$ & LK2H10 & \\
\hline Saline & $0.078 \pm 0.016$ & $0.051 \pm 0.018$ & $0.020 \pm 0.000$ & $0.043 \pm 0.001$ \\
Low & $0.078 \pm 0.005$ & $0.050 \pm 0.010$ & $0.024 \pm 0.003$ & $0.043 \pm 0.010$ \\
High & $0.072 \pm 0.026$ & $0.069 \pm 0.029$ & $0.020 \pm 0.006$ & $(n=5)$ \\
\hline
\end{tabular}




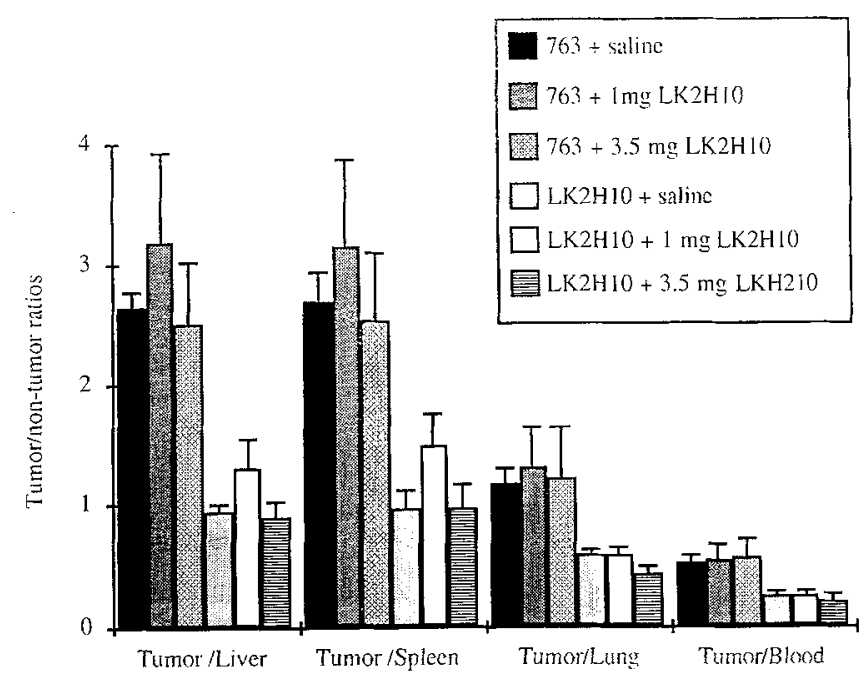

Fig. 2. Mean $\pm S E M$ of tumor/nontumor uptake ratios for 763 and LK2H10 antibodies 8 days after injection. Note the lack of significant difference within the specific antibody and the nonspecific antibody groups. By contrast, the localization of the specific 763 was significantly better than that of the nonmelanoma-specific $\mathrm{LKH} 210$

Table 3. Mean tumor weights $(\mathrm{g}) \pm$ SEM at sacrifice

\begin{tabular}{lll}
\hline Predose & $\mathrm{Ab}-1 / 225.28 \mathrm{~S}$ & LK2H10/763.24T \\
\hline Saline & $0.611 \pm 0.048$ & $0.218 \pm 0.018$ \\
Low & $0.390 \pm 0.113$ & $0.265 \pm 0.144$ \\
High & $0.340 \pm 0.113$ & $0.132 \pm 0.018$
\end{tabular}

No significant difference existed among the tumor weights of the IgG2a (Ab-1/225.28S) groups or among the IgGl (LK2H10/ 763.24T) groups by ANOVA

\section{Discussion}

These studies indicated that no alteration is seen in the biodistribution of two different anti-melanoma monoclonal antibodies with specificity for the same high molecular weight antigen of human melanoma following varying levels of predosing with nonspecific isotype-matched murine monoclonal antibodies. The study also showed no visible alteration in the biodistribution of the nonspecific antibodies. This result is of considerable interest, in that if less specific antibody uptake was to have been seen in the liver, lung, and spleen, following nonspecific antibody pretreatment, then this approach might diminish or eliminate the need for antibody fragmentation for imaging purposes. In many systems, this latter approach has produced higher target/nontarget ratios then the use of comparable intact antibodies [17]. This approach is not always applicable or convenient, as some monoclonal antibodies are difficult or impossible to digest to $F\left(a^{\prime}\right)_{2}$ fragments in replicable or acceptable yields such as IgM and IgG2bs [12].

It is conceivable that even at the high doses of antibody used $(3.5 \mathrm{mg}$ in a $20 \mathrm{~g}$ mouse extrapolates to $12.25 \mathrm{~g}$ in a human) that the F-C receptors in the organs of interest are not fully saturated. However, with polyclonal immune globulin, doses in the gram range have been given and apparently have resulted in RES blockade [2,8]. With a monoclonal anti-F-C receptor antibody, doses of $25-42 \mathrm{mg}$ have shown a transient effect [2]. It is probable that doses of antibody larger than $12 \mathrm{~g}$ would be unrealistic and certainly expensive in man. It is also possible that if $\mathrm{F}-\mathrm{C}$ blockade was achieved, diminished F-C binding may not be the sole reason for the higher target/nontarget levels achieved in vivo by antibody fragments. It is possible that the smaller size of the $F\left(a b^{\prime}\right)_{2}$ fragments versus intact antibody may contribute to improved tumor/nontumor ratios $[7,17]$. Nonetheless F-C binding and its abgroation are certainly likely to be very imprtant since preliminary data suggest that deletions of selective domains of the mouse immunoglobulin molecule $(\mathrm{C} 2 \mathrm{H}$ or $\mathrm{C} 3 \mathrm{H})$ will result in behavior similar to that of the $\mathrm{F}\left(\mathrm{ab} \mathrm{b}^{\prime}\right)_{2}$ fragments, with faster clearance and higher target/nontarget levels of antibody [14]. This was not seen in our study of antibody predosing, where despite high predose levels, no difference in tissue levels including blood levels of monoclonal antibodies were seen 7 days after injection. While it is conceivable that had time points earlier than 7 days after injection been examined, more of an effect would have been seen with predosing, 7 to 8 days was chosen for sacrific as in general delays in this range following monoclonal injection result in superior tumor/nontumor uptake then earlier sampling [17]. Of possible relevance is the suggestion that intact antibody with F-C present may be interacting with circulating antigen in tumor systems and result in RES uptake [7]. The antigen recognized by $225.28 \mathrm{~S}$ is not heavily shed (Wilson BS unpublished data) and thus immune complexe uptake may not be as likely in this system.

Our study demonstrated that even extremely high doses of nonspecific monoclonal antibody given shortly before the administration of specific monoclonal antibody do not significantly alter the specific or nonspecific radioiodinated monoclonal antibody delivery to the tumor target or to nontarget tissues in this human melanoma xenograft system. Results with biosynthetically labeled or metal-chelated antibody might also be different, as a saturable hepatic receptor for ${ }^{111}$ In antibodies may be present [11]. It is also conceivable that earlier sacrifice times might have demonstrated a reduction in nontumor tissue uptake in labeled antibody with predosing, however since maximal relative uptake of antibody to tumor is late, the lack of any change in late uptake makes earlier uptake differences improbable. The evaluation of differences at early time points may be of interest, however in view of the use of shorter-lived isotopes than iodine in imaging studies. An awareness of this phenomenon of nonenhancement of relative tumor uptake with iodinated antibodies should allow for the more rational design of clinical studies and may spare patients unnecessary exposure to high levels of unlabeled nonspecific foreign antibody molecules.

Acknowledgements. Supported by CA40497 awarded by the Public Health Service (RW) and the DOE contract \#DEACO276EV02031 (WHB).

Thanks to Mrs. Michele Bell for excellent typing. The technical assistance of Ms. Linda Laino and Mrs. Gayle Jackson are appreciated.

\section{References}

1. Buraggi GL, Callegaro L, Mariani G et al. (1985) Imaging with ${ }^{\mid 31}$ I-labeled monoclonal antibodies to a high-molecularweight melanoma-associated antigen in patients with melanoma: Efficacy of whole immunoglobulin and tis $F\left(a b^{3}\right)_{2}$ fragments. Cancer Res 45(7): 3378 
2. Clarkson SB, Bussel JB, Kimberly RP et al. (1986) Treatment of refractory immune thrombocytopenic purpura with an anti-Fc receptor antibody. N Engl J Med 314(19): 1236

3. Colcher D, Zalutsky M, Kaplan W et al. (1983) Radiolocalization of human mammary tumors in athymic mice by a monoclonal antibody. Cancer Res 43: 736

4. Ey P, Prowse $S$, Jenkins C (1978) Isolation of pure $\operatorname{IgG}_{1}$, $\mathrm{IgG}_{2 \mathrm{a}}$, and $\mathrm{IgG}_{2 b}$ from mouse serum using protein A-sepharose. Immunochemistry 15:429

5. Giacomini P, Veglia F, Cordiali-Fei $P$ et al. (1984) Level of membrane-bound high-molecular-weight melanoma-associated antigen and a cytoplasmic melanoma-associated antigen in surgically removed tissues and in sera from patients with melanoma. Cancer Res 44(3): 1281

6. Ghose T, Ferrone S, Imia K et al. (1982) Imaging of human melanoma xenografts in nude mice with a radiolabeled monoclonal antibody. J Natl Cancer Inst 69: 823

7. Halpern SE, Buchegger F, Schreyer M, Mach J-P (1984) Effect of size of radiolabeled antibody and fragements on tumor uptake and distribution in nephrectomized mice. $\mathbf{J}$ Nucl Med 25(5): 112

8. Imbach P, Barandun S, d'Apuzzo V et al. (1981) High-dose intravenous gamma-globulin for idiopathic thrombocytopenic purpura in childhood. Lancet I: 1228

9. Laemmli VK (1970) Cleavage of structural proteins during assembly of the head bacteriophage T4. Nature 222: 680

10. Lindmo T, Boven E, Cuttitta F, et al. (1984) Determination of the immunoreactive fraction of radiolabeled monoclonal antibodies by linear extrapolation to binding at infinite antigen excess. J Immunol Methods 72: 77

11. Otsuka FL, Welch MJ (1986) Attempts to saturate the hepatic clearance mechanism for (In-111) labeled monoclonal antibodies. J Nucl Med 27(6): 921

12. Parham P (1983) On the fragmentation of monoclonal IgGl, IgG2a, and IgG2b from BALB/c mice. J Immunol 131(6): 2895

13. Pierce Chemical Product Guide, Pierce Chemical, Rockford, Ill., USA
14. Shah SA, Pollock RR, Brown BA et al. (1986) Pharmacokinetics and imaging using mutant monoclonal anti-ARS antibodies. Proc of AACR 27:335

15. Siccardi AG, Buraggi GL, Callegaro L et al. (1986) Multicenter study of immunoscintigraphy with radiolabeled monoclonal antibodies in patients with melanoma. Cancer Res 46(9): 4817

16. Stauss HW, Carrasquillo JA, Larson SM (1985) Antibody imaging: The smoke, the fire and the false alarm. Int $J$ Nucl Med Biol 12(5): 401

17. Wahl RL, Parker CW, Philpott GW (1983) Improved radioimaging and tumor localization with monoclonal $F\left(a b^{\prime}\right)_{2} . J$ Nucl Med 24: 316

18. Wahl RL, Philpott GW, Parker CW (1983) Monoclonal antibody radioimmunodetection of human-derived colon cancer. Invest Rad 18: 58

19. Wahl RL, Sherman P, Fisher S (1984) The effect of specimen processing on radiolabeled monoclonal antibody biodistribution. Eur J Nucl Med 9(8): 382

20. Wahl RL, Liebert M, Carey JE, et al. (1986) Quality control of radiolabeled monoclonal antibodies: Immunologic and radiochemical. Cancer Drug Deliv 2(3): 236

21. Wilson BS, Lloyd RV (1984) Detection of chromogranin in neuroendocrine cells with a monoclonal antibody. Am J Pathol 115: 458

22. Wilson BS, Imai K, Natali PG, Ferrone S (1981) Distribution and molecular characterization of a cell surface and cytoplasmic antigen detectable in human melanoma cells with monoclonal antibodies. Int J Cancer 28: 293

23. Wilson BS, Platt JL, Kay NE (1985) Monoclonal antibodies to the $140,000 \mathrm{~mol}$ at glycoprotein B-lymphocyte membranes (CR2 receptor) initiates proliferation of B-cells in vitro. Blood 66(4): 824

Received September 29, 1986/Accepted January 20, 1987 